\title{
Knowledge, Attitude and Practice of Diabetic Patients Towards Foot Care at Al-Daraga Health Center, Wad Madani Al Kubra Locality, Gezira State, Sudan, (2020)
}

\section{Dr. Imad Eldin Eljack Suleiman Ahmed}

Ph.D. Department of family and community medicine, University of Gezira, Sudan

\section{Dr. Gamal Mustafa Abdalla Ahmed}

Associate professor of surgery, department of surgery at faculty of medicine, University of Gezira, Sudan

\author{
Dr. Sami Hayati Ahmed Abu Nayeb* \\ PHC, MOHAP. U.A.E \\ * Corresponding Author Email: abunayeb@gmail.com
}

\begin{abstract}
Background: The incidence of foot ulcers ranges from $8 \%$ to $17 \%$ [Crawford F, Inkster M, Kleijnen J, Fahey 2007] and others like peripheral neuropathy, peripheral arterial disease.

Objectives: The aim of the study is to identify the knowledge, attitude and practice of diabetic patients on foot care.

Patients and Methods: Across-sectional study of randomly selected 360 patients of diabetic patients that attend at Al-Daraga Health Center, Wad Madani, Al Kubra locality, Gezira state, during period of one-month 2020. Data was collected via face-to-face interviews by using questionnaire and analyzed by (SPSS).
\end{abstract}


Results: The results showed that there is excellent knowledge about diabetes complications, complications $(94,4 \%)$, and that there is high knowledge of taking medications regularly to prevent complications $(82.2 \%)$, about practicing such as washing feet daily and changing socks daily._Consultation of doctors when any symptoms appeared were good with knowledge more than $50 \%$ of each. But there's lack of knowledge by more than $50 \%$ for things such as washing the feet by warm water with water temperature checked, and dried feet after washed. There is a lack of practicing with more than 50\%, about things such as checking the feet daily and checking the shoes before wearing. Conclusion: Not only good knowledge is needed for footcare, but also good attitude and practice are needed. It is necessary to firstly develop awareness of diabetes and the related complications one amongst which is footcare. Certain educational strategies should be established for both doctors and the patients. I recommended establishing a program like group discussion to patients towards footcare. This study will be helpful in providing evidence regarding the importance of foots care and empowered within the diabetic population.

Keywords: Diabetic Patients, Foot Care, Knowledge, Sudan

\section{Introduction}

\subsection{Background}

Diabetes mellitus is increasing globally. Diabetes can lead to many serious complications. This includes foot ulceration, peripheral neuropathy, peripheral arterial disease, or amputation, which is twice as common as in people with diabetes when compared with healthy individuals. Foot ulceration is the worst complication for diabetic patient, the incidence of foot ulcers ranges from $8 \%$ to $17 \%$ (Crawford et al., 2007). As the incidence of diabetes increases, this can lead to more foot complications and even amputation. In diabetes, peripheral nerve dysfunction can be combined with peripheral artery disease (PAD) causing poor blood circulation to the extremities (diabetic angiopathy). Around half of the patients with a diabetic foot ulcer have co-existing PAD. 
The smallest blister, bug bite or foot sore could lead to a difficult-to-heal foot infection, a skin ulcer and even the possibility of amputation.

The American Diabetes Association recommends that people with diabetes should have a comprehensive foot examination once per year. Proper attitude and practices can be accomplished by washing feet every day in warm (not hot) water, drying feet completely and applying lotion to the top and bottom - but not between toes, which could lead to infection. Never to walk barefoot. Always to wear shoes and socks or slippers, even inside, to avoid injury.

\subsection{Problem Statement}

The prevalence of Diabetes Mellitus In 2017 was estimated that 425 million adults aged 2079 suffered diabetes worldwide and expected to rise to 629 million by 2045. The estimated prevalence of DM in Africa in 2017 was 3.3\%, and Sudan was among the countries that had a prevalence of DM of more than $12 \%$. Diabetic foot ulcer is a common complication of diabetes, with incidents as high as $25 \%$. It is estimated that approximately $50 \%-70 \%$ of lower limb amputation are due to diabetic foot ulcer. And between 9 and $20 \%$ of foot ulcers lead to amputations in the United States.

\subsection{Rationale}

It is necessary to know about the patients related factors behind these foot complications. I assume that patients can play major role in the prevention if they have good knowledge and their attitude and practice towards diabetes and foot care are correct. So, it is important to assess their knowledge, attitude and practice towards diabetes and foot care during their daily life. Foot amputation has great psychological impact on patients and their families. The gap of knowledge and attitude and wrong practice may explain why foot problems are increasing and may reflect the lack of health education towards these patients.

Few studies about this problem were done in Sudan. 


\subsection{Objectives}

\section{General Objective}

To assess the knowledge, attitude and practice of diabetic patients towards foot care.

2. Specific Objectives: -

$>$ To identify the effect of socio-economic status of diabetic patients on foot care.

\section{Literature Review}

Diabetes mellitus (DM), commonly known as diabetes, is a group of metabolic disorders characterized by a high blood sugar level over a prolonged period of time Symptoms often include frequent urination, increased thirst and increased appetite If left untreated, diabetes can cause many health complications. Acute complications can include diabetic ketoacidosis, hyperosmolar hyperglycemic state, or death. Serious long-term complications include cardiovascular disease, stroke, chronic kidney disease, foot ulcers, damage to the nerves, damage to the eyes and cognitive impairment.

Clinical trials related to diabetic foot problems are more often focused on therapeutic or diagnostic issues than on prevention. Here are some studies different areas that address prevention and with same objectives of this study.

In India, Taksande BA, Thote M, Jajoo U N. Knowledge, attitude, and practice of foot care in patients with diabetes at central rural India, The study showed that less education, poor socioeconomic status, and unawareness of foot care were contributing factors of improper footwear practices, which increases the risk for diabetic foot. 
In Brazil, a study on Knowledge, attitudes and practices for the prevention of diabetic foot was done for the same purpose (2014). In terms of practice, results showed that activities such as washing, drying, moisturizing and massaging were not executed together. It is therefore necessary to develop educational strategies to create awareness, for both diabetics and health professionals, on the effective prevention of diabetic foot (MakkiAwouda et al., 2014).

"In Ethiopia, Knowledge, Practice, and Barriers of Foot Care among Diabetic Patients Attending Felege Hiwot Referral Hospital, Bahir Dar, Northwest Ethiopia The aim of this study was to assess knowledge, practice, and barriers of diabetic foot self-care among diabetic patients attending Felege Hiwot Referral Hospital. Method. Institution based descriptive cross-sectional study was conducted on 313 diabetic patients using convenient sampling technique".

Furthermore, a study in Siri Lanka indicated that more than 50\% of the study sample had knowledge on diabetic foot care principles but practice is substandard. Among all diabetic foot care principles, only regular foot observation was carried out by $65.5 \%$. The practice of other foot care principles was below $50 \%$.

\section{Methodology}

\subsection{Study Design}

Cross sectional descriptive facility-based study.

\subsection{Study Area}

Wad Madani is the capital of the Al Gezira state in east- central Sudan. Wad Madani lies on the west bank of the Blue Nile, the border in the north is bounded by nearly about $186 \mathrm{~km}$ south of Khartoum the capital of Sudan. It is surrounded by Al Gezira scheme project from north, east and south. 
Its commercial center for Gezira State. There is Wad Madani teaching hospital and University of Gezira. There are around thirty primary healthcare centers with around ninety physicians. It is connected with many localities and villages.

\subsection{Study setting}

This is facility based, at Al Daragah diabetic center in City of Wad Medani. The center is serving around 300 to 400 patients per day. Out of the total number 100 to 150 are diabetics. There are two consultant specialists medical and surgical and around five general practitioners. The center run under health insurance fund. It is working six days per week.

\subsection{Study Period}

From October to Nov 2020.

\subsection{Study Population}

All diabetic attending the CENTER from age 18 years and above including type 1 and type 2.

\subsubsection{Inclusion criteria}

All diabetic patients attending the center and willing to participate in this study.

Age above 18 years.

\subsubsection{Exclusion criteria}

Those who are not willing to be part of this study

- Those with foot complications.

- Age less than 18 years. 


\subsection{Sample size:}

Since this is a cross sectional study with simple random sampling technique. All patients with inclusion criteria and attend the health center in the period between November and December 2020 and participated represented study population. Since the study population is known, we calculated the sample size through the following formula: Where $\mathrm{n}$ is the sample size and $\mathrm{N}$ is the population size and $\mathrm{e}$ is marginal error $=0.05$

Estimated population size $=150$ (diabetic patients daily) $\times 24$

$($ working days per month $)=3600$

Calculated sample (n) size will be 3600

Participants (cases) in the minimum throughout the study period $(3600+1)(0.05)^{2}$ The sample size per day $=360 / 24=15$ patients per day.

\subsection{Sampling technique}

Systematic sampling is a type of sampling method in which sample members from a larger population were selected according to a random starting point but with a fixed, periodic interval. The sample size per day is 15 , and the total number of the attendants per day is 150 . So, the interval is equal to 150 over 15 which is equal to 10 . After that, I selected randomly from 1 to 9 an initial number, and the chosen number is 1 . Therefore, my sampling numeric set will be 1,11,21,31,41,51, etc until I reach 141 .

\subsection{Data Collection}

Data was collected through direct interviewing using standard questionnaire for Knowledge assessment and Nottingham foot assessment tool for attitude and practice assessment. 
The Nottingham Assessment of Functional Footcare (NAFF) (Lincoln et al, 2007) is a 29 item self-report measure of the extent to which people comply with recommended foot care behaviors. It was developed by converting into question format the information from printed leaflets available in hospitals and podiatry departments in Nottingham and Derby. It was designed to identify people who were not engaging in recommended foot care practice, and to be used as an outcome measure for a trial of education for people with healed foot ulcers to prevent recurrence (Lincoln et al, 2008).I adopted 18 items that was suitable to my participants. The interviewer was health provider who got good training in data collection. Variables: Knowledge variables such as washing foot daily, taking medication regularly, changing socks daily, and not to walk barefoot. Whereas practice variables are checking foot daily and dry between toes after washing. Attitude variables are things such as type of footwear, changing socks daily, walking barefoot, and wearing new shoes immediately.

\subsection{Data Analysis}

Will follow the statistical rule for analysis using the SPSS version 25.

\subsection{Data Presentation}

In the form of tables and charts.

\subsection{Ethical consideration}

- This research proposal was approved by the Research Ethics Committee of University of Gezira -Sudan and Aldaraga Diabetic center authority for ethical and methodological approval.

- An informed consent was obtained from the selected patients. 
Academic Journal of Research and Scientific Publishing | Vol 3 | Issue 26

Publication Date: 5-6-2021 ISSN: 2706-6495

- Patient will be given very clear and conclusive talk about is needed data from them. The consent was in a simple wording and language and with enough period of time before collection.

\section{Results}

Majority of participants were males (59.4\%), age between (35-54) year was 50.1\%, $22.7 \%$ was aged between 15-34 and around 25\% was above 55 years, single more than married $62.5 \%$ and 37,5 respectively, urban more than rural $65 \%$ and $35 \%$ respectively, secondary school education were more than other items $60 \%$, and for occupational category employee was the most $39.7 \%$.

Tables 1, 2 and 3 show frequency of distribution of knowledge about foot care among diabetic patients of selected sample $n=360$

Table 1:

\begin{tabular}{|l|l|l|l|l|l|l|l|l|l|l|}
\hline $\begin{array}{l}\text { Que } \\
\text { stion }\end{array}$ & $\begin{array}{l}\text { Do you know } \\
\text { about } \\
\text { complications } \\
\text { of diabetes }\end{array}$ & $\begin{array}{l}\text { Do you know } \\
\text { you should take } \\
\text { medicine } \\
\text { regularly }\end{array}$ & $\begin{array}{l}\text { Do you know } \\
\text { feet should be } \\
\text { washed daily. }\end{array}$ & \multicolumn{2}{l|}{$\begin{array}{l}\text { Do you know } \\
\text { warm water } \\
\text { should be used }\end{array}$} & $\begin{array}{l}\text { Do you know } \\
\text { water } \\
\text { temperature } \\
\text { must be } \\
\text { checked }\end{array}$ \\
\hline $\begin{array}{l}\text { Res } \\
\text { pons } \\
\text { e }\end{array}$ & $\begin{array}{l}\text { Freq } \\
\text { uenc } \\
\text { y }\end{array}$ & $\begin{array}{l}\text { PERCE } \\
\text { NTAG } \\
\text { E }\end{array}$ & $\begin{array}{l}\text { Freq } \\
\text { uenc } \\
\text { y }\end{array}$ & $\begin{array}{l}\text { PERCE } \\
\text { NTAG } \\
\text { E }\end{array}$ & $\begin{array}{l}\text { Freq } \\
\text { uenc } \\
\text { y }\end{array}$ & $\begin{array}{l}\text { PERCE } \\
\text { NTAG } \\
\text { E }\end{array}$ & $\begin{array}{l}\text { Freq } \\
\text { uenc } \\
\text { y }\end{array}$ & $\begin{array}{l}\text { PERCE } \\
\text { NTAG } \\
\text { E }\end{array}$ & $\begin{array}{l}\text { Freq } \\
\text { uenc } \\
\text { y }\end{array}$ & $\begin{array}{l}\text { PERCE } \\
\text { NTAG } \\
\text { E }\end{array}$ \\
\hline YES & 340 & 94.4 & 296 & 82.2 & 286 & 79.4 & 170 & 47.2 & 104 & 28.9 \\
\hline NO & 8 & 2.2 & 48 & 13.3 & 17 & 4.7 & 151 & 41.9 & 197 & 54.7 \\
\hline $\begin{array}{l}\text { NO } \\
\text { T } \\
\text { SUR } \\
\text { E }\end{array}$ & 12 & 3.3 & 16 & 4.4 & 57 & 15.8 & 39 & 10.8 & 59 & 16.4 \\
\hline $\begin{array}{l}\text { TOT } \\
\text { AL }\end{array}$ & 360 & 100 & 360 & 100 & 360 & 100 & 360 & 100 & 360 & 100 \\
\hline
\end{tabular}


Academic Journal of Research and Scientific Publishing | Vol 3 | Issue 26

Publication Date: 5-6-2021 ISSN: 2706-6495

Table 2

\begin{tabular}{|c|c|c|c|c|c|c|c|c|c|c|}
\hline $\begin{array}{l}\text { Que } \\
\text { stion }\end{array}$ & \multicolumn{2}{|c|}{$\begin{array}{l}\text { Do you know } \\
\text { the soles of the } \\
\text { shoes should be } \\
\text { examine d } \\
\text { before wearing } \\
\text { the shoes }\end{array}$} & \multicolumn{2}{|c|}{$\begin{array}{l}\text { Do you know } \\
\text { you should } \\
\text { consult a doctor } \\
\text { in the event of } \\
\text { an injury or any } \\
\text { symptom in the } \\
\text { feet }\end{array}$} & \multicolumn{2}{|c|}{$\begin{array}{l}\text { Do you know } \\
\text { feet should be } \\
\text { dried after } \\
\text { washing }\end{array}$} & \multicolumn{2}{|c|}{$\begin{array}{l}\text { Do you know } \\
\text { you should put } \\
\text { talcum powder } \\
\text { between toes }\end{array}$} & \multicolumn{2}{|c|}{$\begin{array}{l}\text { Do you should } \\
\text { put a } \\
\text { moisturizer top } \\
\text { on feet }\end{array}$} \\
\hline $\begin{array}{l}\text { Res } \\
\text { pons } \\
\text { e }\end{array}$ & $\begin{array}{l}\text { Freq } \\
\text { uenc } \\
\text { y }\end{array}$ & $\begin{array}{l}\text { PERCE } \\
\text { NTAG } \\
\text { E }\end{array}$ & $\begin{array}{l}\text { Freq } \\
\text { uenc } \\
y\end{array}$ & $\begin{array}{l}\text { PERCE } \\
\text { NTAG } \\
\text { E }\end{array}$ & $\begin{array}{l}\text { Freq } \\
\text { uenc } \\
\mathrm{y}\end{array}$ & $\begin{array}{l}\text { PERCE } \\
\text { NTAG } \\
\text { E }\end{array}$ & $\begin{array}{l}\text { Freq } \\
\text { uenc } \\
y\end{array}$ & $\begin{array}{l}\text { PERCE } \\
\text { NTAG } \\
\text { E }\end{array}$ & $\begin{array}{l}\text { Freq } \\
\text { uenc } \\
y\end{array}$ & $\begin{array}{l}\text { PERCE } \\
\text { NTAG } \\
\text { E }\end{array}$ \\
\hline YES & 170 & 47.2 & 287 & 79.7 & 106 & 29.4 & 150 & 41.7 & 171 & 47.5 \\
\hline NO & 46 & 12.8 & 31 & 8.6 & 166 & 46.1 & 145 & 40.3 & 98 & 27.2 \\
\hline $\begin{array}{l}\text { NO } \\
\text { T } \\
\text { SUR } \\
\text { E } \\
\end{array}$ & 144 & 40.0 & 42 & 11.7 & 88 & 24.4 & 65 & 18.1 & 91 & 25.3 \\
\hline $\begin{array}{l}\text { TOT } \\
\text { AL }\end{array}$ & 360 & 100.0 & 360 & 100 & 360 & 100 & 360 & 100 & 360 & 100 \\
\hline
\end{tabular}

Table 3

\begin{tabular}{|c|c|c|c|c|c|c|c|c|c|c|}
\hline $\begin{array}{l}\text { Que } \\
\text { stion }\end{array}$ & \multicolumn{2}{|c|}{$\begin{array}{l}\text { Do you know } \\
\text { soother should } \\
\text { not be placed } \\
\text { between the } \\
\text { toes }\end{array}$} & \multicolumn{2}{|c|}{$\begin{array}{l}\text { Do you know } \\
\text { you should } \\
\text { change socks } \\
\text { daily }\end{array}$} & \multicolumn{2}{|c|}{$\begin{array}{l}\text { Do you know } \\
\text { the nails should } \\
\text { be trimmed so } \\
\text { that the edge of } \\
\text { the nail is } \\
\text { straight }\end{array}$} & \multicolumn{2}{|c|}{$\begin{array}{l}\text { Do you know } \\
\text { feet should be } \\
\text { checked daily } \\
\text { by the patient }\end{array}$} & \multicolumn{2}{|c|}{$\begin{array}{l}\text { Do you know } \\
\text { the shoes must } \\
\text { be comfortable }\end{array}$} \\
\hline $\begin{array}{l}\text { Res } \\
\text { pons } \\
\text { e }\end{array}$ & $\begin{array}{l}\text { Freq } \\
\text { uenc } \\
y\end{array}$ & $\begin{array}{l}\text { PERCE } \\
\text { NTAG } \\
\text { E }\end{array}$ & $\begin{array}{l}\text { Freq } \\
\text { uenc } \\
\mathrm{y}\end{array}$ & $\begin{array}{l}\text { PERCE } \\
\text { NTAG } \\
\text { E }\end{array}$ & $\begin{array}{l}\text { Freq } \\
\text { uenc } \\
y\end{array}$ & $\begin{array}{l}\text { PERCE } \\
\text { NTAG } \\
\text { E }\end{array}$ & $\begin{array}{l}\text { Freq } \\
\text { uenc } \\
\mathrm{y}\end{array}$ & $\begin{array}{l}\text { PERCE } \\
\text { NTAG } \\
\text { E }\end{array}$ & $\begin{array}{l}\text { Freq } \\
\text { uenc } \\
y\end{array}$ & $\begin{array}{l}\text { PERCE } \\
\text { NTAG } \\
\text { E }\end{array}$ \\
\hline YES & 202 & 56.1 & 226 & 62.8 & 194 & 53.9 & 217 & 60.3 & 189 & 52.5 \\
\hline $\mathrm{NO}$ & 50 & 13.9 & 50 & 13.9 & 62 & 17.2 & 55 & 15.3 & 69 & 19.2 \\
\hline $\begin{array}{l}\text { NO } \\
\text { T }\end{array}$ & 108 & 30.0 & 84 & 23.3 & 104 & 28.9 & 88 & 24.4 & 102 & 28.3 \\
\hline
\end{tabular}


Academic Journal of Research and Scientific Publishing | Vol 3 | Issue 26

Publication Date: 5-6-2021 ISSN: 2706-6495

\begin{tabular}{|l|l|l|l|l|l|l|l|l|l|l|}
\hline $\begin{array}{l}\text { SUR } \\
\text { E }\end{array}$ & & & & & & & & & & \\
\hline $\begin{array}{l}\text { TOT } \\
\text { AL }\end{array}$ & 360 & 100.0 & 360 & 100.0 & 360 & 100.0 & 360 & 100.0 & 360 & 100.0 \\
\hline
\end{tabular}

In the light of above tables, it is clear that Majority of participants were known about DM, complications, medications, prevention, and foot care carefully.

Same noticeable result from the previous tables as the following:

- $60 \%$ of the selected sample do check their feet regularly, compare to around $23 \%$ were rarely check their feet or not at all. In regard to washing the feet only $31 \%$ washed their feet regularly while the majority washed infrequently this group represent $35 \%$ followed by $32 \%$ not washing at all.

- drying the feet and between the toes among selected sample the majority of participants sometimes do.

\section{Discussion}

According to this study results a total patients of diabetes mellitus sample selected 360 participants, attended Al Daragah diabetic center in City of Wad Medani in Gezira State, Sudan.

Regarding the socio-demographic characteristics of diabetic patients; the majority of participants were males more than females 214(59.4\%), age ranged between 35-44 years old about 101(28.1\%), about 2/3 of participants from urban area $234(65 \%)$,

The low education level abundant than higher education. About 8 items of occupation an employee were more than others which is $143(37.8 \%)$, single were more than married 225(62.5\%). More than 50\% from participants have diabetes mellitus duration between 510 years $(57.8 \%)$. about $2 / 3$ has family history of diabetes mellitus (64.7\%), in diabetic complications developed foot complication its first (67.2\%) this agrees with previous study (Al-Maskari, M. El-Sadig Prevalence of risk factors for diabetic foot complications BMC Fam Pract, (2007), second kidney more than others (47.5\%). 
More than 50\% (184 participants) increased compliance and more than 59\% treated by injection $(58.6 \%),(56.9 \%)$ from participants were smoker.

There is excellent health education on diabetes mellitus (98.6\%) and foot care $(95,8 \%)$ There are two source of health education received, first one is physicians (53.6\%) and diabetic center (46,4\%). This is supported by a previous study in Sudan, Effects of Health Education of Diabetic Patient's Knowledge at Diabetic Health Centers, Khartoum State (2014).

About knowledge, there is an excellent knowledge about knowledge in DM, complications $340(94,4 \%)$, there were increased knowledge about taking medications regularly to prevent complications 296 (82.2\%), also there is good knowledge about washing feet daily 286 (79.4\%), changing socks daily 226(62.8\%), trimming the edge of nails straight 194 (53.9\%), checking feet daily 217 (60.3\%).Diabetic patients should wear comfortable shoes $189(52.5 \%)$, wipe the feet with a lotion or Vaseline, and consultation of doctors when any symptoms appeared 287(79.7\%).

But there's lack of knowledge by less than $50 \%$ for, the feet should be washed with warm water $(47.2 \%)$, checked temperature of water (28.9\%), dried feet after washed (29.4\%), placed talcum powder between toes (41\%), moisturizer feet (47.5\%), and soles of the shoes should be examined before worn.

Considering attitude and practice of participants, despite good knowledge discussed above , there was lack of practicing of less than 50\% in checking the feet daily, checking the shoes before wearing, washing the feet with soap and warm water daily, feeling the water temperature before use, drying the feet and between the toes after washing, wipe the feet with a lotion or Vaseline daily, trim the nails in a circular shape and straight line, used sandal, used narrow boots, used sport shoes, used the new shoes immediately and constantly, used boots without socks, and walking barefoot.

Comparing the results of this study with similar studies. In Saudi Arabia study was done by AL-HARIRI, M. T., AL-ENAZI, A. S., ALSHAMMARI, D. M., BAHAMDAN, A. S., ALKHTANI, S. M. \& AL-ABDULWAHAB, A. A. 2017.. This study was done at King Fahad hospital of the university of Dammam. 
The results showed high knowledge but the self-footcare is not satisfactory. This agrees with the result of this study, which also showed high knowledge and poor self-footcare. The other study was done in Philippines by MAGBANUA, E. \& LIM-ALBA, R. 2017. The study was done at Chinese General Hospital and Medical Centre. The results showed that participant had good knowledge, but the level of self-footcare is not satisfactory. This supports the result of this study. In India, study was done by TAKSANDE, B. A., THOTE, M. \& JAJOO, U. 2017. This study was done at Rural Hospital outpatient. The result showed that patients with low socio-economic status and low educational level had poor knowledge and poor selffootcare. This again agrees with the result of this study. In United Arabs of Emirates, a study was done by AL-MASKARI, F. \& EL-SADIG, M. 2007. The result of this study also showed that patient with poor foot-selfcare had low educational level, which supports the results of this study. In Sudan, study was done in Jabir Abu-Alaiz Diabetic Centre in Khartoum in 2007. The result of the study showed that health education on diabetic patient increased the knowledge about diabetes and footcare. This also supports the results of this study patient had high knowledge because they got health education by physicians and in diabetic center. Good knowledge with gaps in attitude and practice are common results between this study and other studies.

\section{Conclusion and Recommendations}

\subsection{Conclusion}

- This study concluded that diabetic patients showed socio-demographic characteristics of more males in gender, age ranged between 35-44years old, about $2 / 3$ of participants from urban, and the low education level abundant than higher education.

Employees were more than others.

- About diabetes complications, they developed foot complication followed by kidney complication.

- Smokers were of high percentage. 
- There was an excellent health education on diabetes mellitus and footcare received from physicians and diabetic center.

- Participants have an excellent knowledge about DM and footcare.

- The practice and attitude of participants towards footcare were poor compared to their good knowledge towards footcare.

\subsection{Recommendations:}

- At the level of Ministry of health is to establish more diabetic health centers with specialized team, training of more diabetic educators, dieticians and implementation more health education programs.

- At the level of Health centers should is to organize special sessions on footcare practices and attitude with group of diabetic patients. Health centers also should perform audits on comprehensive foot examination annually or frequently if needed in order to assess and improve health providers performance.

- Healthcare providers should focus on addressing gaps in foot care knowledge, supporting proper foot care practices and encouraging diabetic patients to participate in educational activities on diabetes.

- At the level of community more health education can be done by making use of the media, mosques and public gathering so as to raise the awareness and importance of foot care by diabetic patients and their families.

- Smoking cessation should be given great priority and importance and introduction of smoking cessation programs at broader aspects.

\section{Acknowledgement}

I give my acknowledgement to the university of Gezira for giving me the opportunity and the steppingstone of my career. I also give it to the eminent teachers, family medicine department, my supervisor Dr. Imad, and to my collogues. 


\section{Reference}

- $\quad$ CRAWFORD, F., INKSTER, M., KLEIJNEN, J. \& FAHEY, T. 2007. Predicting foot ulcers in patients with diabetes: a systematic review and meta-analysis. Journal of the Association of Physicians, 100, 65-86.

- $\quad$ TAKSANDE, B. A., THOTE, M. \& JAJOO, U. 2017. Knowledge, attitude, and practice of foot care in patients with diabetes at central rural India. Journal of family medicine and primary care, 6, 284.

- $\quad$ Awole Sied and Yosief Tsige 2014.

- MAKKIAWOUDA, F. O., ELMUKASHFI, T. A. \& AL-TOM, S. A. H. 2014. Effects of health education of diabetic patient's knowledge at Diabetic Health Centers, Khartoum State, Sudan: 2007-2010. Global journal of health science, 6, 221.

- $\quad$ AL-MASKARI, F. \& EL-SADIG, M. 2007. Prevalence of risk factors for diabetic foot complications. BMC Family practice, 8, 59.

- $\quad$ ALJOUDI, A. S. \& TAHA, A. Z. 2009. Knowledge of diabetes risk factors and preventive measures among attendees of a primary care center in eastern Saudi Arabia. Annals of Saudi medicine, 29, 15-19.

- C. V. M. Jinadasa and M. Jeewantha, "A study to determine theknowledge and practice of foot care in patients with chronicdiabetic ulcers, 'International Journal of Collaborative Researchon Internal Medicine \& Public Health, vol. 3, pp. 115-122, 2011

- MAKKIAWOUDA, F. O., ELMUKASHFI, T. A. \& AL-TOM, S. A. H. 2014. Effects of health education of diabetic patient's knowledge at Diabetic Health Centers, Khartoum State, Sudan: 2007-2010. Global journal of health science, 6, 221.

- $\quad$ AL-HARIRI, M. T., AL-ENAZI, A. S., ALSHAMMARI, D. M., BAHAMDAN, A. S., AL-KHTANI, S. M. \& AL-

- $\quad$ ABDULWAHAB, A. A. 2017. Descriptive study on the knowledge, attitudes and practices regarding the diabetic foot. Journal of Taibah University Medical Sciences, 12, 492-496. 
- N. B. Lincoln, W. J. Jeffcoate, P. Ince, M. Smith, and K. A.Radford, "Validation of a new measure of protective footcarebehaviour: the Nottingham Assessment of Functional Footcare(NAFF),'Practical Diabetes International,vol.24,no.4,pp.207-211, 2007.+-

- MAGBANUA, E. \& LIM-ALBA, R. 2017. Knowledge and Practice of Diabetic Foot Care in Patients with Diabetes at Chinese General Hospital and Medical Center. Journal of the ASEAN Federation of Endocrine Societies, 32, 123-123.

- TAKSANDE, B. A., THOTE, M. \& JAJOO, U. 2017. Knowledge, attitude, and practice of foot care in patients with diabetes at central rural India. Journal of family medicine and primary care, 6, 284.

- AL-MASKARI, F. \& EL-SADIG, M. 2007. Prevalence of risk factors for diabetic foot complications. BMC Family practice, 8, 59.

Copyright ( 2021 Dr. Imad Eldin Eljack Suleiman Ahmed, Dr. Gamal Mustafa Abdalla Ahmed, Dr. Sami Hayati Ahmed Abu Nayeb, AJRSP. This is an open-access article distributed under the terms of the Creative Commons Attribution License (CC BY NC).

Doi: doi.org/10.52132/Ajrsp.e.2021.265 